\title{
Effect of heat treatment and hot working on microstructure and mechanical properties of a novel nickel base superalloy
}

\author{
R. V. Shakhov' ${ }^{1}$ A. A. Ganeev ${ }^{1}$, Sh. Kh. Mukhtarov ${ }^{1, \dagger}$, A. V. Logunov ${ }^{2}$ \\ †shamil@anrb.ru \\ ${ }^{1}$ Institute for Metals Superplasticity Problems of RAS, 39 Khalturin str., Ufa, 450001, Russia \\ ${ }^{2}$ PJSC “UEC-Saturn”, 163 Lenin Ave., Rybinsk, 152903, Russia
}

\begin{abstract}
The microstructure and mechanical properties of a novel nickel base superalloy intended for manufacturing of die tools and parts for gas turbine engine have been investigated. The superalloy designated as SLZhS-1R had the following composition: $\mathrm{Ni}-47(\mathrm{Al}, \mathrm{Cr}, \mathrm{Co}, \mathrm{Ta}, \mathrm{W}, \mathrm{Hf})-0.2(\mathrm{C}, \mathrm{B})$ (wt. \%). The as-cast superalloy was subjected to homogenization and heterogenization heat treatment, which is typically performed before hot working. However, the heat treatment led to appearance of platelike precipitates, which are not favorable for the hot workability. Therefore, the superalloy was subjected to hot working taking the as-cast condition as the initial one. To do it, unidirectional hot forging at a temperature slightly below the $\gamma^{\prime}$ solvus temperature with a strain rate of $\varepsilon^{\prime} \sim 10^{-2} \mathrm{~s}^{-1}$ was carried out. The as-cast superalloy showed reasonable workability that allowed producing sound forgings. The forging procedure provided formation of mixed microstructure consisted of coarse non-recrystallized and fine recrystallized $\gamma$ grains. EBSD analysis of the forged workpiece showed that the fraction of highangle grain boundaries was insignificant. The hot forging resulted in dynamic recovery, whereas recrystallization processes occurred only locally near the $\gamma$ grain boundaries. Tensile tests were carried out for the heat treated and hot forged conditions as well as for the as-cast condition. The heat treated and especially the forged and heat treated condition showed appreciably higher strength and ductility as compared to those of the cast condition. The obtained tensile properties were compared with those of the widely applied Russian superalloy ZhS6U.
\end{abstract}

Keywords: nickel base superalloy, microstructure, $\gamma^{\prime}$ phase, hot forging, mechanical properties.

\section{Introduction}

Improving gas turbine engine (GTE) performance for rockets and airplanes requires development of new materials and technologies that would meet the increasing operational demands due to the increase in temperature and loading of components [1]. The use of rare-earth elements and single crystal technologies is very costly and effective alloying with common refractory elements that would provide effective solid solution hardening is of great practical interest [2-7]. However, higher alloying with refractory elements can lead to formation of topologically close-packed phases during long-term high temperature exposure [8]. Thus, the alloying additions should be precisely chosen to avoid formation of undesirable phases.

The present work is devoted to study of microstructure and mechanical properties of a novel nickel base superalloy with a higher content of $\mathrm{Co}$ and $\mathrm{W}$ produced by casting. The obtained mechanical properties are to be compared with properties of the Russian nickel base superalloy ZhS6U widely used for manufacturing of die tools and blades for gas turbine engines.

\section{Experimental Procedures}

The nickel base superalloy $\mathrm{Ni}-47(\mathrm{Al}, \mathrm{Cr}, \mathrm{Co}, \mathrm{Ta}, \mathrm{W}, \mathrm{Hf})-$ $0.2(\mathrm{C}, \mathrm{B})$ (wt. \%) designated throughout the text as SLZhS-1R was taken as a starting material. The as-cast ingot with a size of $\varnothing 45 \times 270 \mathrm{~mm}$ was produced by the Russian enterprise STC "TSM" Ltd. The dissolution temperature of the $\gamma^{\prime}$ phase $\left(T_{s}\right)$ was determined by differential scanning calorimetry and quenching experiments. The solvus temperature was $T_{s}=1185 \pm 5^{\circ} \mathrm{C}$. The as-cast ingot material was subjected to homogenization and heterogenization heat treatments $[1,9]$, which included multiple solid-solution treatments at temperatures around $T_{s}$ followed by slow cooling to coagulate the $\gamma^{\prime}$ phase. The as-cast superalloy was subjected to unidirectional hot forging at a temperature slightly below the $\gamma^{\prime}$ solvus temperature with a strain rate of $\varepsilon^{\prime} \sim 10^{-2} \mathrm{~s}^{-1}$. The post-forging heat treatment consisted of solid solution treatment at temperature slightly below the solvus temperature and two stage aging at $T=1000$ and $850^{\circ} \mathrm{C}$ with air cooling after each aging stage. To evaluate the hot forging influence on mechanical properties, the same heat treatment was used with respect to the cast material. The heat treated and forged plus heat treated materials were used to prepare samples for tensile testing. The tensile tests were made using the samples with a gage section of $15 \times 5 \times 1.5 \mathrm{~mm}^{3}$.

The microstructure examination was carried out using scanning electron microscopy (SEM) in backscattering electron (BSE) mode. Electron backscattered diffraction (EBSD) analysis was performed with a scan-step size of 2-6 $\mu \mathrm{m}$. In doing so, the $\gamma^{\prime}$ precipitates were assumed as the $\gamma$ phase and the microstructure was assumed as quasisingle-phase. EBSD analysis was conducted using the CHANNEL 5 processing software. The grain boundaries 
having misorientation angle less than $2^{\circ}$ were excluded from consideration taking into account the measurement accuracy. The grain boundaries having misorientation angle more than $15^{\circ}$ were considered as high-angle boundaries. The average $\gamma$ grain size was evaluated using EBSD data.

\section{Results and discussion}

\subsection{Initial as-cast microstructure}

Fig. 1 represents BSE images of the as-cast superalloy obtained at different magnifications. The microstructure consisted of coarse $\gamma$ dendrites (Fig. 1a) banded with nonequilibrium eutectic and small carbides (Fig. 1b). Precipitates of the $\gamma^{\prime}$ phase (ordered $\mathrm{Ni}_{3}(\mathrm{Al}, \mathrm{Ti})$, superlattice $\mathrm{L}_{2}$ ) were homogeneously distributed and had a size of $0.1-0.2 \mu \mathrm{m}$ (Fig. 1c) [1,2]. The volume fraction of the $\gamma^{\prime}$ phase was defined as about $60 \%$.

Fig. 2 shows the EBSD orientation map and the corresponding misorientation-angle distribution for grain boundaries obtained for the as-cast condition. One can see that dendritic structure constitutes coarse elongated $\gamma$ grains with a length up to $2-3 \mathrm{~mm}$ and a width of $50-500 \mu \mathrm{m}$ (Fig. 2a). The misorientation-angle distribution for grain boundaries shows that mostly high-angle boundaries were observed: their fraction was found to be $76.5 \%$. Note that EBSD image is agreed with the BSE images but gives a clearer vision of the coarse dendritic structure.

\subsection{Effect of processing on the as-cast microstructure}

It is well known that homogenization and heterogenization heat treatment reduces the level of dendritic segregation and leads to coagulation of the $\gamma^{\prime}$ precipitates. Such heat treatment is typically carried out to enhance the hot workability and to facilitate recrystallization processes in nickel base superalloys during hot working $[1,9]$.

Fig. 3 shows the BSE images of the superalloy after twostage and multiple homogenization and heterogenization heat treatments. One can see that nonequilibrium eutectic completely dissolved and transformed into a coarse-grained structure with a grain size of $100-200 \mu \mathrm{m}$. Small carbides containing heavy elements were transformed into round particles with a larger size. The $\gamma^{\prime}$ precipitates were coagulated and their size increased up to $0.5-2.5 \mu \mathrm{m}$ (Fig. 3b). However, plate-like precipitates were also detected within $\gamma$ grains. One can see that these precipitates were smaller after two-stage heat treatment and became coarser after multi-stage heat treatment (Fig. 3b,c). The size of the plate-like precipitates reached up to $20 \mu \mathrm{m}$ in length (Fig. 3c). As is known, coarse plate-like precipitates are unfavorable for hot workability [2]. Reasoning from this, the hot working was carried out for the as-cast superalloy without any preliminary heat treatment.

Fig. 4 shows BSE images obtained from the central part of the forged workpiece. The hot forging led to formation

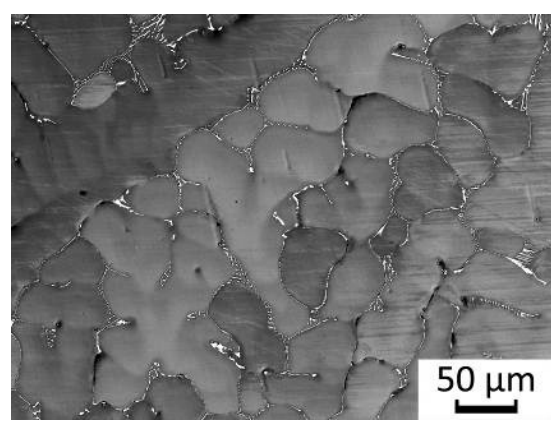

a

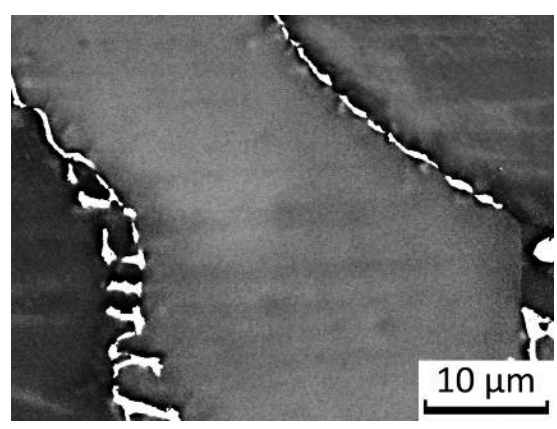

b

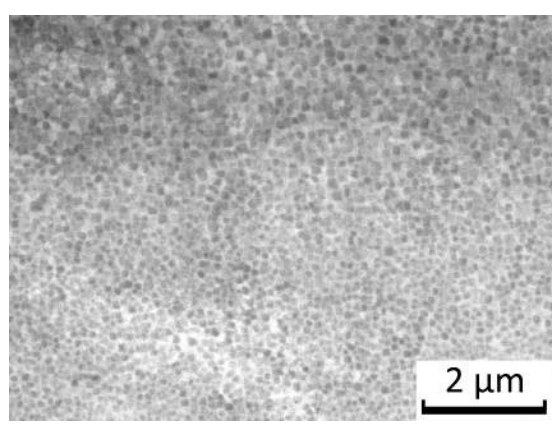

c

Fig. 1. BSE images of the superalloy SLZhS-1R in as-cast condition obtained at different magnifications: coarse $\gamma$ dendrites (a), nonequilibrium eutectic (b), $\gamma^{\prime}$ phase (c).
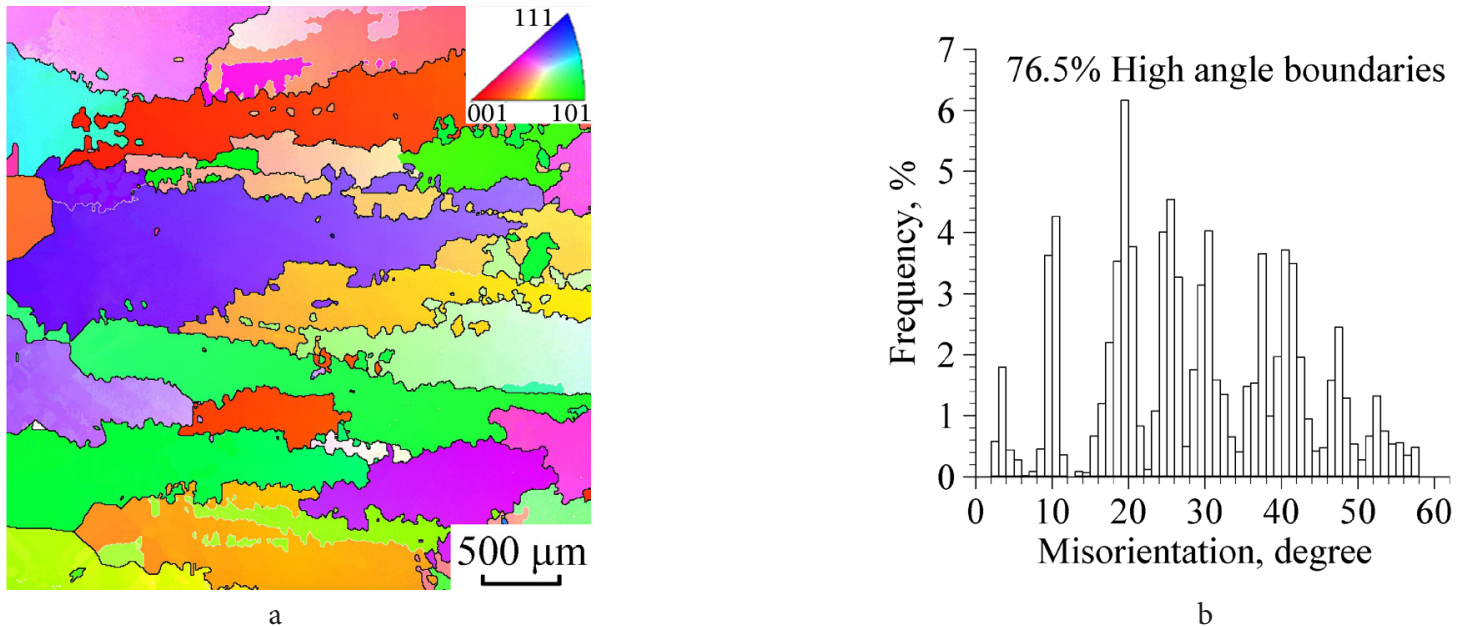

b

Fig. 2. EBSD orientation map (a) and the corresponding misorientation-angle distribution for grain boundaries (b) obtained for the superalloy SLZhS-1R in as-cast condition. 
of mixed microstructure consisted of mostly coarse nonrecrystallized $\gamma$ grains with a size of $50-300 \mu \mathrm{m}$ and fine recrystallized $\gamma$ grains with a size of 5-10 $\mu \mathrm{m}$. Particles containing heavy elements were uniformly distributed along the initial $\gamma$ grain boundaries. The size of $\gamma^{\prime}$ precipitates was around $0.2-0.3 \mu \mathrm{m}$ (Fig. $4 \mathrm{~b}$ ).

EBSD analysis confirmed that recrystallization processes occurred only locally near the $\gamma$ grain boundaries (Fig. 5a). One can see that the microstructure after hot forging was generally coarse grained. The misorientation-angle distribution for grain boundaries shows that mostly low-angle boundaries were obtained after hot forging: the fraction of high-angle grain boundaries was found only $16.7 \%$ (Fig. 5b). This suggests that hot forging resulted in dynamic recovery, whereas recrystallization processes occurred only locally near the $\gamma$ grain boundaries.

The hot forged material was subjected to hardening heat treatment. The same heat treatment was also applied for the as-cast material in order to evaluate the effect of the hot forging on the tensile properties. Figs. 6 and 7 represent BSE images of the superalloy after hot forging and hardening heat treatment and after the same heat treatment of the cast material, respectively.

The forged and heat treated material consisted of coarse $\gamma$ grains and recrystallized fine $\gamma$ grains (Fig. 6a). Plate-like precipitates were not detected. The $\gamma^{\prime}$ precipitates had a size of $0.2-0.35 \mu \mathrm{m}$ (Fig. 6b). The heat treated cast alloy had a coarse grained structure with a small amount of plate-like precipitates located near $\gamma$ grain boundaries (Fig. 7a). The $\gamma^{\prime}$ precipitates were homogeneously distributed in $\gamma$ grains and had a size of $0.15-0.2 \mu \mathrm{m}$ (Fig. 7b). Thus, the forged and heat treated condition was finer grained, whereas the size of the $\gamma^{\prime}$ precipitates was slightly coarser than in the cast and heat treated condition.

\subsection{Tensile properties of the superalloy SLZhS-1R after processing}

Table 1 represents the tensile properties of the superalloy in different conditions. One can see that in spite of a low efficiency of the hot forging, the forged and heat treated condition showed appreciably higher strength as compared to the other conditions. This can be ascribed to the presence of fine recrystallized grains, the developed subgrain structure, and the absence of plate-like precipitates. Rather low ductility is likely associated with appearance of unfavorable phases during heat treatment.

The comparison of the tensile properties of the superalloy under study and the Russian superalloy ZhS6U in the cast condition shows that the novel superalloy possesses quite promising mechanical properties. Further investigations are required to specify the alloy composition and the hot working conditions that would provide more extensive occurrence of recrystallization processes.

\section{Conclusions}

The novel nickel base superalloy SLZhS-1R (Ni-47(Al,Cr,Co,Ta,W,Hf)-0.2(C,B), wt.\%) with a higher content of refractory elements and containing about $60 \mathrm{vol} . \%$ of the $\gamma^{\prime}$ phase has been preliminary investigated from the viewpoint of the hot workability and tensile

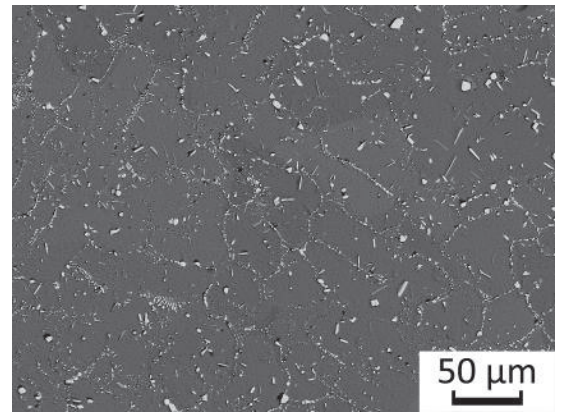

a

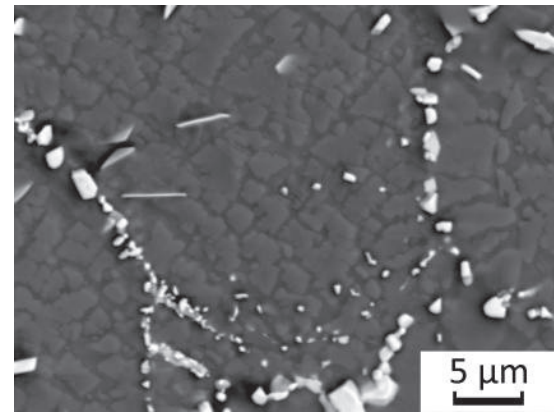

b

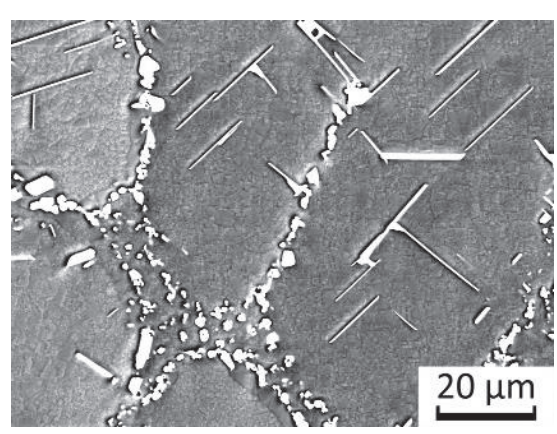

c

Fig. 3. BSE images of the superalloy SLZhS-1R obtained for the cast condition subjected to homogenization and heterogenization heat treatment: after two-stage heat treatment $(a, b)$, after multiple heat treatment $(c)$.

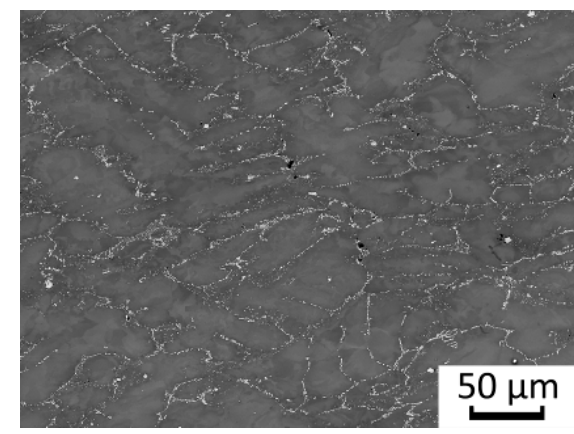

a

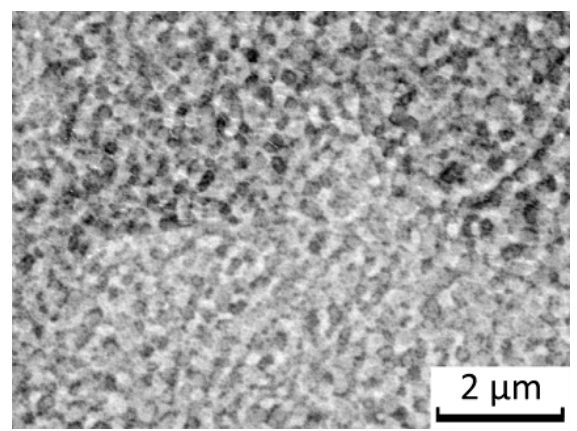

$\mathrm{b}$

Fig. 4. BSE images of the superalloy SLZhS-1R subjected to hot forging starting from the as-cast condition at temperatures slightly below the solvus temperature: forged microstructure (a), $\gamma^{\prime}$ phase (b). 

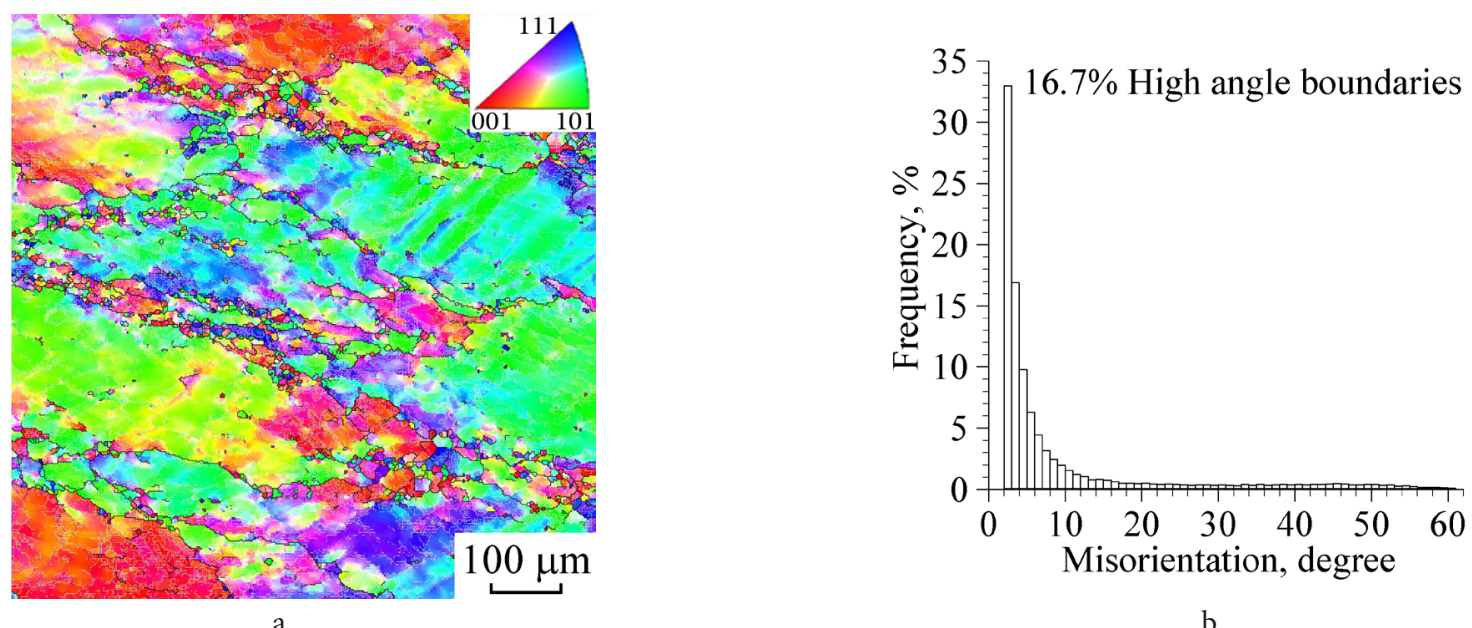

b

Fig. 5. EBSD orientation map (a) and the corresponding misorientation-angle distribution for grain boundaries (b) obtained for the cast superalloy SLZhS-1R subjected to hot forging at temperatures slightly below the solvus temperature.

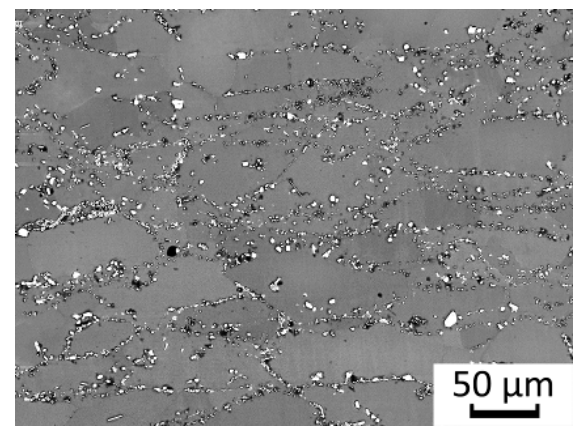

a

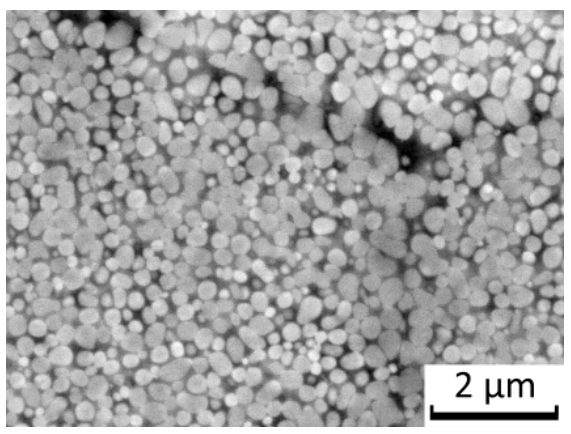

$\mathrm{b}$

Fig. 6. BSE images of the superalloy SLZhS-1R subjected to hot forging and hardening heat treatment (a) and $\gamma^{\prime}$ phase (b).

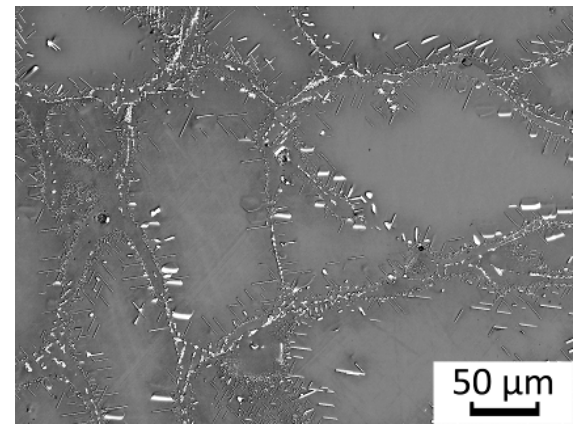

a

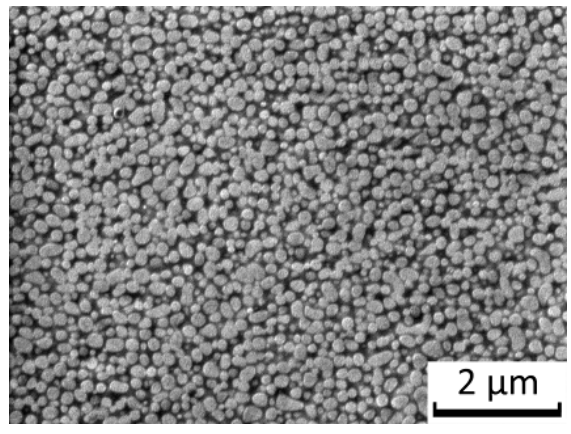

$\mathrm{b}$

Fig. 7. BSE images of the cast superalloy SLZhS-1R subjected to hardening heat treatment (a), $\gamma^{\prime}$ phase (b).

Table 1. Tensile properties of the superalloy under study and the Russian superalloy ZhS6U in the cast condition (HT — heat treatment, HF - hot forging).

\begin{tabular}{|c|c|c|c|c|}
\hline Alloy / condition & $t,{ }^{\circ} \mathrm{C}$ & UTS, MPa & YS, MPa & $\delta, \%$ \\
\hline Ni-47(Al,Cr,Co,Ta,W,Hf)-0.2(C,B) / & 20 & 946 & 922 & 1.0 \\
as-cast & 650 & 858 & 856 & 0.8 \\
\hline Ni-47(Al,Cr,Co,Ta,W,Hf)-0.2(C,B) / & 20 & 1030 & 900 & 5.2 \\
cast + HT & 650 & 938 & 965 & 2.4 \\
\hline Ni-47(Al,Cr,Co,Ta,W,Hf)-0.2(C,B) / \\
cast + HF + HT & 20 & 1129 & 1220 & 0.8 \\
\hline ZhS6U [10] / cast & 20 & $920-970$ & - & $3.0-6.0$ \\
\hline ZhS6U [11] / cast & 20 & 830 & - & 3.0 \\
\hline
\end{tabular}


properties. The superalloy showed quite good workability at temperatures slightly below the solvus temperature. The superalloy subjected to hot forging followed by heat treatment demonstrated reasonable tensile properties: $\sigma_{\mathrm{UTS}} / \sigma_{0.2}=1129 / 960 \mathrm{MPa}$ at room temperature and $\sigma_{\text {UTS }}{ }^{650} / \sigma_{0.2}{ }^{650}=1244 / 1200 \mathrm{MPa}$ at $T=650^{\circ} \mathrm{C}$ while retaining acceptable ductility. Further investigations are required to specify the alloy composition and the processing parameters.

Acknowledgements. The reported study was accomplished according to the state assignment of IMSP RAS (AAAA-A17-117041310215-4) and partially funded by the Russian Foundation for Basic Research according to the research project № 18-08-00997-a. The work was performed using the facilities of the shared services center «Structural and Physical-Mechanical Studies of Materials» at the Institute for Metals Superplasticity Problems of Russian Academy of Sciences.

\section{References}

1. R.C. Reed. The superalloys: Fundamentals and Applications. Cambridge University Press (2006) 372 p.

2. C. T. Sims, N. S. Stoloff, W. C. Hagel. Superalloys II: High-
Temperature Materials for Aerospace and Industrial Power. New York, John Wiley \& Sons, Inc. (1987) 615 p.

3. A. Sato, H. Harada, A-C. Yeh, K. Kawagishi, T. Kobayashi, Y. Koizumi, T. Yokokawa, J-X. Zhang. Superalloys. 2008, 131 (2008)

4. S. B. Feng, X. H. Luo. Journal of Physics: Conf. Series. 327, 012006 (2011). DOI: 10.1088/1742-6596/327/1/012006

5. H. Long, S. Mao, Y. Liu, Z. Zhang, X. Han. J. All. Compd. 743, 203 (2018).

6. B. Zhang, C.-H. Tao, X. Lu, C.-K. Liu, C.-Y. Hu, M.-Y. Bai. J. Iron Steel Res. Internat. 16, 75 (2009).

7. L. Cao, P. Wollgramm, D. Bürger, A. Kostka, G. Cailletaud, G. Eggeler. Acta Mater. 158, 381 (2018).

8. F. Sun, J. Zhang. Adv. Mater. Res. 320, 26 (2011). DOI: 10.4028/www.scientific.net/AMR.320.26

9. O.A. Kaibyshev, F.Z. Utyashev. Superplasticity: Microstructural Refinement and Superplastic Roll Forming. Futurepast Arlington, Virginia USA, ISTC Science and Technology Series, 3 (2005) 386 p.

10. V.M. Polyanskii, V.V. Gavrilyuk, V.Z. Zagorskii, A. V. Logunov, A. M. Polyanskii, M. I. Silis, Met. Sci. Heat Treat. 46, 392 (2004).

11. Industry standard $190126-85$. Cast alloys heat-resistant vacuum melting. 11 p. (in Russian) 